\title{
VARIEDADES
}

\section{LOS FALSOS SAGUNT DE LAS FUENTES ÁRABES}

\section{FALSE SAGUNT IN ARABIC SOURCES}

\author{
CARMEN BARCELÓ \\ Universidad de Valencia
}

En fechas recientes he dedicado varios trabajos a estudiar el topónimo valenciano Morvedre ${ }^{1}$, nombre antiguo de la actual Sagunto. Esto me ha llevado a replantearme el problema de la identificación y localización de los hipotéticos «Sagunto» que aparecen en las fuentes árabes al narrar sendas revueltas acaecidas en los años 172/778-789 y 317/929-930.

Mi punto de partida se sigue basando en el hecho de que la existencia de un doblete Sagunto-Morvedre sería un insólito caso andalusí de uso simultáneo de dos denominaciones romances; una de ellas, además, ofrecería grafías dispares en las crónicas ( $\breve{S} a g n t, B s \bar{a}^{t} t$ en 172; Smgws, Šgwns en 317). Por otro lado, en la descripción de al-Andalus de al-Rāzī (m. 344/955) se llama al lugar Morvedre, nunca Sagunto.

Me ocuparé del tema ahora para ofrecer nuevas propuestas, distintas a las que presenté en su día para localizar esos lugares ${ }^{2}$.

${ }^{1}$ Barceló, C., "Làpida funerària de Murbātitir (Sagunt, segle X)", Stvdia Philologica Valentina, 5 (2001), 169-177; idem, "Paseo toponímico de Sagunt a Saguntum", en J.R. Hinojosa Montalbo (comisario), De Murbiter a Morvedre, Sagunto, 2006, 13-20; idem, "Sagunt i el seu territori a l'època àrab", Braçal. Revista del Centre d'Estudis del Camp de Morvedre, 35-36 (2007), 65-93.

2 Barceló, C., "¿Galgos o podencos? Sobre la supuesta berberización del País Valenciano en los siglos VIII y IX", Al-Qanțara, XI (1990), 429-460, en especial 444-446 y 456-457. 


\section{El hịsn Smgws}

Según la obra de Ibn Hayyān ${ }^{3}$ y la Crónica Anónima de 'Abd al-Rahmān III ${ }^{4}$, en 317/929 se rindieron Xàtiva y otra fortaleza, hasta entonces en manos del rebelde beréber 'Āmir b. Abī Ŷawšan. Se deduce que la caída de ambas (ciudad y fortaleza) fue simultánea y que el castillo tendría algún significado que le hizo merecedor de ser citado. La grafía de su nombre nos ha llegado en sendos mss. únicos, cuyos ductus editados son Smgws en la obra de Ibn Hayyān y Šgwns en la Crónica Anónima de 'Abd al-Raḥmān III.

La forma Šgwns recuerda las varias Sagontia o Seguntia de las que dan testimonio las fuentes de la Antigüedad. Si ese nombre perduró hasta el siglo VIII y se adaptó al árabe, presentaría grafías escritas del tipo $\breve{S} g w n s(a), \breve{S} g w n s a$ o $\breve{S} g w n s i a^{5}$, pues el grupo -tia ya se había palatizado en buena parte de la antigua Hispania ${ }^{6}$ ( $v . g r$ : Bætia-Bayyāsa-Baeza). Por si ese tipo de nombres de lugar guardara relación con el que nos ocupa, se puede intentar seguirle el rastro; en una búsqueda sin afán exhaustivo, encuentro las siguientes menciones:

1. En el siglo IX la crónica de Ibn Ḥayyān ${ }^{7}$ sitúa por tierras de

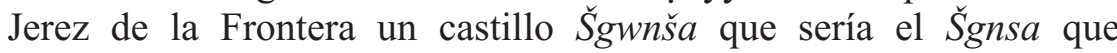
al-'Udrī 8 incluye en un itinerario de la cora de Algeciras-Sidonia. Hace tiempo que se identifica con el municipio gaditano [Baños de] Gigonza, en cuyo término se hallan las ruinas de la Saguntia del conventus Gaditanus ${ }^{9}$.

2. Al-Bakrī ${ }^{10}$ cita una Šagwnsa en la división cuarta de Constantino, que sería la Šagnasa [sic], ciudad próxima a Guadalajara

${ }^{3}$ Chalmeta, P., Corriente, F. y Șubh, M. (eds.), al-Muqtabas V, Madrid-Rabat, 1979, 249, f. 164.

${ }^{4}$ Lévi-Provençal, E. y García Gómez, E. (eds.), Madrid-Granada, 1950, $82 \S 63$.

${ }^{5}$ En el área oriental parece que el proceso no había acabado (v.gr.: Valentia $>$ Balansia pero en Baleares: Pollentia $>$ Bullānsa $>$ Pollensa; cfr. más adelante el caso al-šs'ntī).

6 Barceló, C., "Adaptación arábiga de los topónimos antiguos", en Congrés Internacional de Toponímia i Onomàstica Catalanes, Valencia, 2002, 489-510.

7 Antuña, M.M. (ed.), Muqtabis, París, 1937, 119-120.

8 Al-Ahwānī, A.A. (ed.), Fragmentos geográfico históricos, Madrid, 1965, 117.

9 Roldán Hervás, J.M., Itineraria hispana. Fuentes antiguas para el estudio de las vías romanas en la Península Ibérica, Madrid, 1975, 263.

${ }^{10}$ Van Leeuwen, A.P. y Ferre, A. (eds.), al-Masālik wa-l-mamālik, Túnez, II, 1992, n. ${ }^{\circ} 1491,892$.

Al-Qanțara (AQ) XXX 1, enero-junio 2009, pp. 237-243 ISSN 0211-3589 
mencionada por al-Qazwīn̄ī ${ }^{11}$ a partir de al-'Udrī. Es la misma Segontia que Eulogio ${ }^{12}$ sitúa en el camino de Córdoba a Pamplona, la Sigüenza continuadora de la ciudad arávaca de Segontia del conventus Cluniensis ${ }^{13}$.

3. En el conventus Caesaraugustanus también hubo una Segontia entre Netorbriga (Calatorao) y Zaragoza. Se desconoce su paradero y es posible que no llegara a ser conocida por los árabes, aunque a este topónimo podría aludir el patronímico al- $\check{S}^{\prime} n t \bar{l}$ [sic], que llevaba un sabio de Calatayud, exilado a Murcia después de la conquista cristiana en 514/1120; su nombre se atribuye a un castillo (hisn) en la nāhiya de Calatayud-Daroca ${ }^{14}$.

4. Al-Idrīsī ${ }^{15}$ menciona una Šgwnsa en uno de sus itinerarios de Córdoba a Mérida, a una etapa de Jerez de los Caballeros. No hallo noticia de esta Segontia o Saguntia en las fuentes clásicas. En mi artículo ya citado planteé la posibilidad de que el castillo que nos ocupa fuera ese lugar, sugiriendo una interpolación en los mss. ${ }^{16}$

Está claro, sin embargo, que ninguna de esas Saguntia o Šagwnsa puede ser la fortaleza valenciana.

Volvamos a la tradicional identificación del topónimo con Sagunto. Las grafías Smgws y Šgwns están en abierta contradicción con la adaptación árabe que se esperaría de dicho topónimo: $\breve{S} a g u \bar{n} t$ o $\check{S} a$ gunt. Es difícil aceptar que la $<\mathrm{t}>$ final se confundiera fonéticamente con una $<\mathrm{s}>$, y aún más que se confundiera en su forma escrita.

Ahora bien, ¿se pudo producir error de copia? Si es así, pudo ser entre grafías como $<\mathrm{g}>/<\mathrm{q}>\mathrm{y}<\mathrm{w}>/<\mathrm{r}>$ cuya vacilación es habitual en los mss.

Si cambiamos esas dos letras, en la Crónica Anónima tenemos la grafía Šqrns y en Ibn Hayyān, Smqrs. Esta última forma nos da la clave para interpretar correctamente el topónimo, ya que admite ser leída

11 Ātār al-bilād wa-ajbār al- 'ibād, Dar Sader publishers, Beirut, 541. III, 73).

12 Gil, J. (ed.), Corpvs Scriptorvm Mvzarabicorum, Madrid, II, 1973, 500 (Eul. ep.

13 Roldán Hervás, Itineraria hispana, 266. Los restos de la antigua ciudad se hallan a sólo $3 \mathrm{~km}$ de la moderna.

${ }_{14}$ Ibidem, 266; Ibn al-Abbār, Takmila, F. Codera (ed.), Madrid, II, 1889, b. 1665, 597.

15 Mizal, J.A. (ed.), Los caminos de al-Andalus en el siglo XII, Madrid, 1989, 83.

16 Barceló, “¿Galgos o podencos?”, 456-457; en p. 456, la grafía Š.gwnsa de la obra de Ibn Hāyyān citada no se refiere al topónimo extremeño, sino a Gigonza. Es, sin embargo, la misma que ofrece el editor de al-Idrīsī. 
Šumaqars; es decir, la actual Sumacàrcer. Esta población controla el paso natural del Júcar desde Cuenca a Valencia ${ }^{17}$ y se halla en la margen derecha del río, a unos $20 \mathrm{~km}$ de Xàtiva (principal centro de la zona en conflicto a principios del siglo X) y a otros tantos de Alzira (otro lugar controlado por el rebelde 'Āmir b. Abī Ŷawšan).

\section{¿Iqlim de Tortosa?}

Voy a ocuparme ahora de la segunda cita en las fuentes árabes, la de Šāgnt, $B s \bar{a}^{‘} t$. Las ediciones de las obras de Ibn al-Ațīr, Ibn 'Id̄ārī, al-Nuwayrī e Ibn Jaldūn indican — tal vez tomando la noticia de Ibn Hayyān — que en el año 172/778-789 Sa'īd al-Anșārī se rebeló contra el poder omeya en cierto iqlim conocido por Šägnt o Bsā't.

Estas y otras fuentes árabes localizan las acciones de al-Husayn $b$. Yahyà, padre de Sa'īd y socio de Sulaymān al-A'rābī, en la Frontera Superior: zona aragonesa, además de Navarra y tierras carolingias. Por otro lado sabemos que hacia 780-781 Sa'īd huyó al Pallars ${ }^{18}$ e Ibn al-Ațīr y al-Nuwayrī dicen que el rebelde se sublevó en el mismo lugar donde se refugió en 783 tras la muerte de su padre. Por ello resulta extraño que se alejara de un entorno donde habría contado con aliados para buscar refugio en un iqlim que — según las ediciones - pertenecía a Tortosa y se apoderara de esa ciudad expulsando a su 'ámil.

El Bayān de Ibn 'Id̄ārī ${ }^{19}$ fue el primer texto editado que citaba el refugio del rebelde: el iqlīm de Šăgnt de la ciudad de Trtw̧ša o el $S a$ gunto, del Clima de Tortoxa de la traducción de Fernández González ${ }^{20}$. Ibn al-Atîir ${ }^{21}$ y la segunda edición del Bayānn ${ }^{22}$ dan la misma grafía de ambos topónimos y ninguna de esas dos ediciones señala

17 Sobre el castillo de Sumacàrcer, cfr. Bazzana, A. et alii, Les châteaux ruraux d'al-Andalus, Madrid, 1988, en especial 96-99 y 271-275.

${ }^{18}$ Lafuente y Alcántara, E. (ed.), Ajbār Maŷmū'a, Madrid, 1867, 114. Sobre estos hechos de cronología incierta, cfr. Chalmeta, P., Invasión e islamización. La sumisión de Hispania y la formación de al-Andalus, Madrid, 1994, 367 y ss.

19 Ed. R. Dozy, Leiden, II, 1851, 63-64. El editor se basó en un único ms.

${ }^{20}$ Ibn Idari al Marrakusi, Historia de al-Andalus, Madrid, 1869 [reimpr. Málaga, 1999, 92].

${ }_{21}$ Tornberg, C.J. (ed.), Kāmil, Leiden, VI, 1871, 80 [reimpr. Beirut, VI, 117].

22 Lévi-Provençal, E. y Colin, G.S. (eds.), Bayān al-mugrib, Leiden, II, 1951, 62. Corríjase en Barceló, “¿Galgos o podencos?”, 457, donde por errata remite a la p. 22 de esta edición.

Al-Qanțara (AQ) XXX 1, enero-junio 2009, pp. 237-243 ISSN 0211-3589 
variante en los mss. utilizados. En los 'Ibar de Ibn Jaldūn ${ }^{23}$ (que no recoge el nombre del iqlim) el topónimo editado es Trswsa.

Gaspar Remiro, al publicar los fragmentos relativos a al-Andalus de al-Nuwayrī, anotó que en nuestra noticia el ms. de la RAH trae Tršwš́a donde el de París lleva Trtwssa ${ }^{24}$. Aunque tradujo Tortosa, propuso identificar el nombre del iqlim con Beceite y no con Sagunto ${ }^{25}$, como se aceptaba hasta entonces, pues contaba con las grafías $B \check{s} \bar{a} \bar{a}^{\prime} t / B s \bar{a}^{\prime} t$ (pero $<\mathrm{b}>\sin$ punto diacrítico). Así pues, los editores de estas dos crónicas advierten que los mss. difieren en la grafía del nombre de la cora: Trţ̦̌̌a, Trțsa, Tršswša, Trswsa.

Es normal que copistas medievales y modernos confundan la grafía de Tortosa $\left(\operatorname{Trtwša}\right.$ ) con otras similares ${ }^{26}$, como Tarazona (Trswna), Tolosa (Ṭlwša) o la Tarsos oriental (Țrsws). Lo mismo sucede con otros lugares ( $v$. gr:: Zaragoza) y también es normal que en términos que desconocen confundan las letras; y además los editores - salvo excepciones - corrigen o interpretan los textos según su buen criterio, sin incluir en nota las variantes de los mss. o las formas manuscritas originales.

Las ediciones de las obras de Ibn al-Ațīr, Ibn 'Iḍārī, al-Nuwayrī e Ibn Jaldūn recogen otras noticias de fecha próxima al 172, donde se menciona también a Tortosa y su estudio tal vez arroje luz sobre el tema que estamos tratando. Veamos ahora qué dicen esos textos.

En la primera edición del Bayān hay un pasaje ${ }^{27}$, relacionado con la rebelión de Matrūḥ b. Sulaymān al-A'rābī en Zaragoza el año 175/791-792, donde se dice que el militar omeya 'Ubayd Allāh b. 'Uțmān se instaló en Tortosa para combatirle (por eso Fernández González ${ }^{28}$ tradujo Tortoxa). Años después, Dozy decidió que había que modificar ${ }^{29}$ esa localización y señaló que la grafía Trtw̧š del ms.

${ }^{23}$ Ed. Beirut, IV, 1988, 124.

24 "Historia de España y África por En-Nuguairi”, RCEHGR, VI (1916) 174-175, n. ${ }^{\circ} 4$.

25 Ibidem, 174, n. ${ }^{\circ} 3$.

${ }^{26}$ Cfr. Terés, E., Materiales para el estudio de la toponimia hispanoárabe. Nómina fluvial, Madrid, 1986, 60-62; Souto, J.A., "El noroeste de la Frontera Superior de al-Andalus en época omeya: los datos de las fuentes geográficas e históricas (III)", BSEO, XXXI (1995), 62; Bramon, D., De quan érem o no musulmans. Textos del 713 al 1010, Barcelona, 2000, 157, n. ${ }^{\circ} 48,181$, n. ${ }^{\circ} 61,197$ n. ${ }^{\circ} 133$.

27 Dozy, R. (ed.), al-Bayān al-mugrib, Leiden, II, 1851, 65.

28 Ibn Idari al Marrakusi, Historia de al-Andalus [reprint Málaga, 1999, 93].

29 Corrections sur les textes du Bayáno 'l-Mogrib d'Ibn-Adhári, Leiden, 1883, 39.

Al-Qanțara (AQ) XXX 1, enero-junio 2009, pp. 237-243 ISSN 0211-3589 
único usado por él, debía ser corregida como Trswna (esto es, Tarazona) siguiendo el texto del ms. de París de la crónica de al-Nuwayrī.

La segunda edición del Bayān, hecha por Lévi-Provençal y Colin ${ }^{30}$, ofrece la lectura Tarazona sin que se indique al lector que ha sido modificada la grafía del ms. usado por Dozy, ni que haya otra variante. La grafía Trsswna también está presente en Ibn al-Atīir ${ }^{31}$. El editor de los 'Ibar de Ibn Jaldūn ${ }^{32}$ reproduce Trswsa. Por su parte, Gaspar Remiro optó por traducir Tarazona, aunque señaló que el ms. de al-Nuwayrī de la RAH recoge Trsūna (sin puntos) y el de París, Trswsa ${ }^{33}$.

En resumen, en esa noticia — sólo tres años posterior a la que nos interesa - los mss. ofrecen el nombre del topónimo con variantes similares a las ya señaladas en la nuestra: Trțš̌a, Trsw.a, Trswsa. Hoy es comúnmente aceptado que se trata de Tarazona, aduciendo razones de estrategia militar.

Las obras que narran un ataque de Ludovico Pio a tierras andalusíes en 192/807-808 también presentan formas parecidas a las que se atestiguan en nuestra noticia: Trțšsa, Trswna, Trswsa ${ }^{34}$. ¿Cómo se han interpretado las grafías de esta noticia? Hace ya tiempo que con el apoyo de las crónicas francas se justificó la lectura Tortosa.

En el caso que nos ocupa de 172, el ductus de los mss. de las cuatro obras que narran los hechos, permite leer tanto Tortosa como Tarazona, pero se ha aceptado la primera ciudad por el peso que tuvo en el ánimo de editores posteriores la decisión de Dozy: dar por segura la correlación $\breve{S} a g n t=$ Sagunto, aunque él sabía sin duda que en otras fuentes este topónimo aparece escrito Murbițar (el Morvedre medieval).

El lector ya habrá adivinado que mi opción en el pasaje del año 172 es interpretar Tarazona. Desde un punto de vista histórico se explicaría mejor que Sa'īd al-Anșārī contara con apoyos para poder expulsar a su gobernador y que Mūsà b. Fortūn se enfrentara voluntaria-

${ }^{30}$ Lévi-Provençal y Colin, Bayān al-mugrib, 63.

31 Tornberg, Kämil, VI, 86 [reprint Beirut, VI, 123].

32 Ed. Beirut, IV, 124.

33 "Historia de España y África", 174, nota 4 y 175, nota 6, pero según Dozy habría que interpretar Trswna.

${ }^{34}$ Cfr. Millàs, J.M., Textos dels historiadors àrabs referents a la Catalunya Carolíngia, Barcelona, 1987, 111, § 97, nota 3; Bramon, De quan érem o no musulmans, 197, $\S 236$.

Al-Qanțara (AQ) XXX 1, enero-junio 2009, pp. 237-243 ISSN 0211-3589 
mente a Sa‘īd e interviniera en favor del emir Hišām. Conviene recordar que en esos momentos Tarazona era la capital de la cora de su nombre y que además se hallaba a las puertas del territorio donde estuvo el solar de los Banū Qasī.

Sería muy aventurado por mi parte presentar una propuesta de correspondencia de las grafías del nombre del iqlim con algún topónimo de la Frontera Superior. Con todo, aun a riesgo de equivocarme, la forma editada Šăgnt en dos de las crónicas, me lleva a sospechar que tal vez se pueda tratar de Sádaba ( $\check{S} a ̄ d a b a ?)$, lugar del Alto Aragón a unos 75 km de Tarazona y 90 de Zaragoza, en vecindad con las Bardenas Reales. Pero aunque requeriría una modificación mayor, a partir de las grafías $B \check{s}^{\prime}{ }^{\prime} t / B s \bar{a}^{\prime} t$ de al-Nuwayrī, me inclino por proponer Cascante (Qašquānt o Qasqānt?), municipio aragonés que dista unos $95 \mathrm{~km}$ de la capital y se halla a tan sólo $15 \mathrm{~km}$ al norte de Tarazona y a unos 7 al sur de Tudela.

Tras desechar otras posibilidades, propongo ahora que en 172/778-789 Sa'īd al-Anșārī se rebeló en la cora de Tarazona y que el castillo valenciano sometido en 317/929 fue Sumacàrcer. Así quedan mejor explicados los hechos en los que se mencionan dichos lugares, y desaparecen las dos únicas citas de Sagunto en fuentes árabes, suprimiendo las pruebas sobre el uso en al-Andalus de dos nombres romances para una sola población.

Recibido: $27 / 02 / 2007$

Aceptado: 07/06/2007 